\title{
Medicaid Expansion - The Soft Underbelly of Health Care Reform?
}

\section{Citation}

Sommers, Benjamin D., and Arnold M. Epstein. 2010. "Medicaid Expansion - The Soft Underbelly of Health Care Reform?" N Engl J Med 363 (22) (November 25): 2085-2087. doi:10.1056/nejmp1010866.

\section{Published Version}

doi:10.1056/NEJMp1010866

\section{Permanent link}

http://nrs.harvard.edu/urn-3:HUL.InstRepos:26568344

\section{Terms of Use}

This article was downloaded from Harvard University's DASH repository, and is made available under the terms and conditions applicable to Other Posted Material, as set forth at http:// nrs.harvard.edu/urn-3:HUL.InstRepos:dash.current.terms-of-use\#LAA

\section{Share Your Story}

The Harvard community has made this article openly available.

Please share how this access benefits you. Submit a story.

\section{Accessibility}




\section{Medicaid Expansion - The Soft Underbelly of Health Care Reform?}

Benjamin D. Sommers, M.D., Ph.D., and Arnold M. Epstein, M.D.

Txpanding health insurance to cover Americans who are currently uninsured, with the ultimate goal of improving access to care, is arguably the most critical objective of the recently enacted health care reform legislation. In large part, the success or failure of health care reform will hinge on the achievement of this goal.

The Patient Protection and Affordable Care Act (ACA) incorporates two strategies for expanding coverage. First is a mandate for all individuals to purchase insurance, coupled with the creation of state-based insurance "exchanges" and subsidies to help individuals whose incomes are below $400 \%$ of the federal poverty level to purchase coverage from private companies. Second is an expansion of Medicaid, underwritten by the federal government, to cover all adults whose family income is below 133\% of the federal poverty level; children of families with incomes below this cutoff are already eligible for public coverage.

Estimates from the Congressional Budget Office (CBO) suggest that each of these approaches will add 16 million enrollees, for a total of 32 million newly insured Americans. However, there is obvious cause for uncertainty about the estimates of how many will obtain coverage through the insurance exchanges. Debate is already under way about the effectiveness of the mandate, what constitutes a sufficient subsidy, and how the exchanges will be implemented.
By comparison, the effect of the Medicaid expansion would appear to be easier to predict. Because expanded coverage will be free to the states (at least through 2016) and to uninsured persons whose income qualifies them for it, it is tempting to assume that almost all individuals who are eligible will enroll. But eligibility for health insurance does not always translate into actual enrollment - as evidenced by the millions of uninsured adults who are already eligible for Medicaid under current law. Moreover, the apparent simplicity of expanding Medicaid uniformly to include people in a given income category belies the tremendous heterogeneity among the 50 state Medicaid programs, which vary in terms of enrollment procedures, demographics of the target population, and state politics. These differences will complicate any attempt to implement such a broad expansion and cast serious doubt on the precision of predictions about its outcome.

Medicaid is currently characterized by highly variable participation rates among eligible adults in different states. We used data from the 2007 through 2009 Current Population Survey (CPS), a nationally representative survey conducted by the Census Bureau, to estimate state participation rates among U.S. citizens 19 to 64 years of age who are currently eligible for Medicaid and have no other health insurance. The eligibility rules come from public data sources, ${ }^{1-4}$ and our estimates were adjusted for previously documented underreporting of Medicaid coverage in the CPS. ${ }^{5}$ The scatter plot shows the Medicaid participation rates by state on the vertical axis. The horizontal axis indicates the percentage of each state's adult population that will become newly eligible for Medicaid in 2014 under the ACA. In other words, the vertical axis measures how well states currently perform in enrolling eligible adults and the horizontal axis measures the extent of the new task each state will face come 2014.

Three key results emerge from this analysis. First, participation rates are far from ideal, with a national average of $61.7 \%$ of eligible individuals. Second, Medicaid participation is highly variable, with rates ranging from just under $44 \%$ in Oklahoma, Oregon, and Florida to $80 \%$ in Massachusetts and $88 \%$ in the District of Columbia. Third, the states that will have the greatest number of newly eligible adults under health care reform have, if anything, been historically worse (but not significantly so) at finding and keeping eligible adults enrolled in Medicaid (regression coefficient, $-0.46 ; 95 \%$ confidence interval, -1.13 to 0.21 ).

Our knowledge of the factors affecting Medicaid enrollment and retention among eligible adults is incomplete. Administrative obstacles almost surely play a key role. Unless they complete the multipage application and provide documentation of income and residency, eligible individuals sim- 


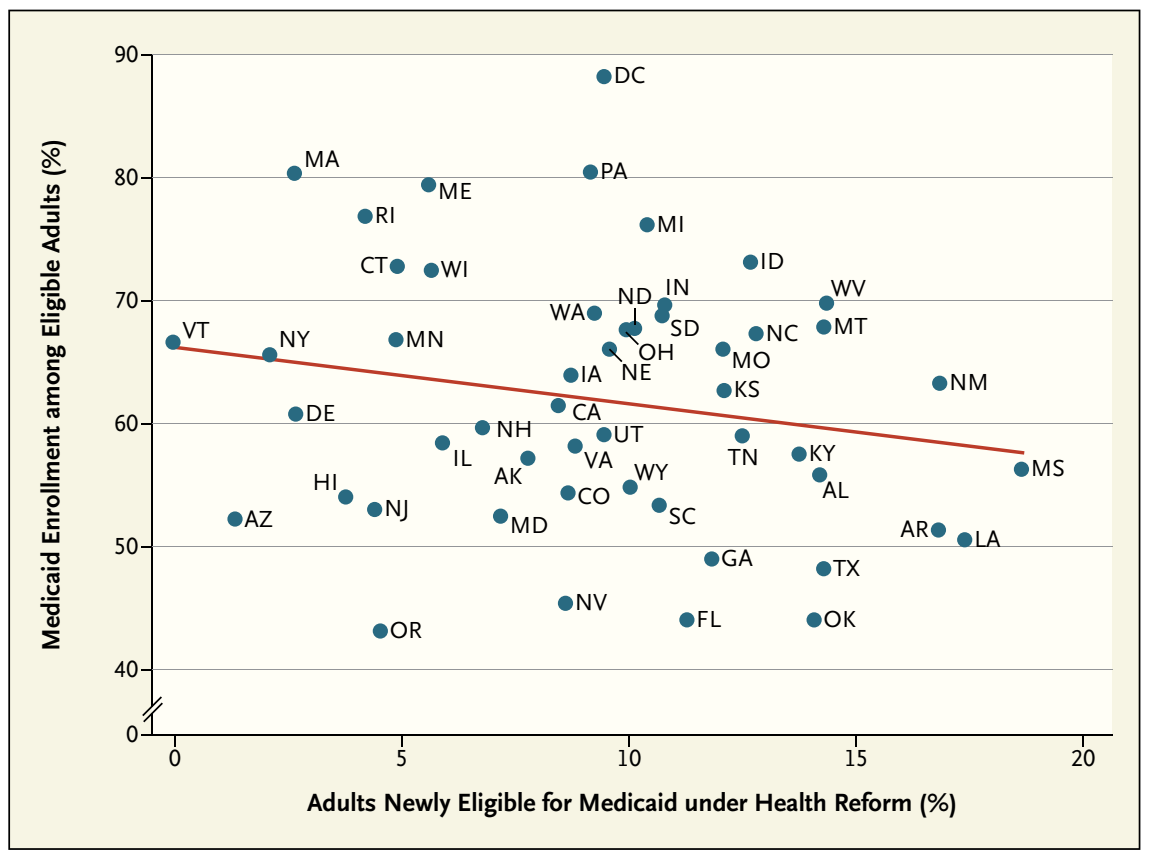

Medicaid Enrollment among Currently Eligible Adults (2007 through 2009) and Percentage of Adults Who Will Become Eligible in 2014 under Health Care Reform, by State.

The population sample was restricted to eligible adults with no other form of health insurance; noncitizens were excluded from the analysis. Results are based on an analysis of data from the Current Population Survey of 2007 through 2009. The red line shows the regression equation: Enrollment $=0.66-0.46 \times$ Newly Eligible $(P=0.17)$.

ply never get enrolled. Maintaining enrollment also poses a challenge, since federal law requires that states verify an enrollee's eligibility annually, and some states choose to do so more frequently. The prevalence and quality of Medicaid managed care, provider reimbursement rates, and outreach efforts may also play a role in enrolling and retaining eligible adults.

Official projections regarding Medicaid enrollment under the ACA come from the $\mathrm{CBO}$, which does not release the details of its calculations. These projections require numerous assumptions about population growth and economic conditions over time, as well as about how many adults will switch from private coverage to Medicaid, and results vary depending on the data source. That said, on the basis of the tors, such as the media attention that will surround the expansion and simplification of eligibility rules, may also lead to higher rates of participation than the program currently enjoys.

However, other factors suggest that takeup rates under the ACA may not even reach current levels of participation, let alone far exceed them. As the regression line on the scatter plot shows, the national average is skewed by higher levels of Medicaid enrollment in states in which the expansion will have less impact because so many of the adults in question are already eligible. Furthermore, newly eligible, higher-income adults may be less familiar with welfare procedures or more sensitive to the stigma of enrolling in a public program than are those who are currently eligible. Adults with disabilities make up a disproportionate share of current Medicaid enrollees, with a traditionally higher participation rate $(79 \%$ in our sample), whereas the overwhelming majority of adults who will become eligible for Medicaid under the ACA do not have a disability. Finally, the federal mandate does not apply to adults with incomes below the Internal Revenue Service tax-filing threshold $(\$ 9,350$ for single adults and $\$ 18,700$ for married adults filing jointly, according to the 2009 rules); in our sample, this group accounted for slightly more than half of all uninsured adults who will be eligible for Medicaid.

The good news is that implementation of the ACA's Medicaid expansion is still more than 3 years away. This window creates a critical opportunity for states to evaluate their Medicaid enrollment procedures and lay the groundwork for a successful expansion. An important issue will 
be how states approach the interactions between the insurance exchanges and Medicaid; adults with incomes close to $133 \%$ of the federal poverty level may not know which program they should apply to, and states should take steps to prevent uninsured adults from falling through the cracks. Other approaches to streamlining Medicaid enrollment will also need to be considered. The natural experiment of having 50 different states with highly variable participation rates offers ample opportunity for exploring the policy options.

The impending Medicaid expansion will be the single biggest change in the program since its inception in 1965. The success of health care reform in im- proving access to care will largely depend on whether newly eligible individuals enroll in Medicaid and remain enrolled. Though the details of enrollment outreach, application processes, and renewal procedures may not be glamorous, they hold the key to success in expanding health insurance coverage to millions of needy Americans.

Disclosure forms provided by the authors are available with the full text of this article at NEJM.org.

From the Department of Health Policy and Management, Harvard School of Public Health, and the Division of General Medicine, Brigham and Women's Hospital both in Boston.

This article (10.1056/NEJMp1010866) was updated on December 29, 2010, at NEJM. org.
1. Where are states today? Medicaid and state-funded coverage eligibility levels for low-income adults. Washington, DC: Kaiser Family Foundation, 2009. (http://www.kff.org/ medicaid/upload/7993.pdf.)

2. Medicaid financial eligibility: primary pathways for the elderly and people with disabilities. Washington, DC: Kaiser Commission on Medicaid and the Uninsured, 2010. (http://www.kff.org/medicaid/8048.cfm.)

3. Ross DC, Horn A, Marks C. 2008. Health coverage for children and families in Medicaid and SCHIP: state efforts face new hurdles. Washington, DC: Kaiser Commission on Medicaid and the Uninsured, 2008. (http://www.kff.org/medicaid/7740.cfm.)

4. Ross DC, Cox L, Marks C. 2007. Resuming the path to health coverage for children and parents: a 50-state update on eligibility rules, enrollment and renewal procedures, and costsharing practices in Medicaid and SCHIP in 2006. Washington, DC: Kaiser Commission on Medicaid and the Uninsured, 2007. (http://www.kff.org/medicaid/7608a.cfm.) 5. Call KT, Davidson G, Davern M, Nyman R. Medicaid undercount and bias to estimates of uninsurance: new estimates and existing evidence. Health Serv Res 2008;43:901-14.

Copyright (c) 2010 Massachusetts Medical Society.

\section{Pharmaceutical Marketing and the New Social Media}

Jeremy A. Greene, M.D., Ph.D., and Aaron S. Kesselheim, M.D., J.D., M.P.H.

\begin{abstract}
Tacebook and Twitter, the largest social media Web sites, have more than 350 million users worldwide, and surveys indicate that $60 \%$ of Americans turn first to the Internet when seeking health-related information. ${ }^{1}$ It is therefore surprising that the pharmaceutical and medical-device industries have been slow to establish a social media presence. The drug industry allocated less than $4 \%$ of the more than $\$ 4$ billion it spent on direct-to-consumer advertising to Internet outlets in 2008 , and only a tiny fraction of that was for social networking sites. ${ }^{2}$ In the next year, however, the proportion may change substantially.

Since the Pure Food and Drug Act was passed in 1906, control by the Food and Drug Administration (FDA) over drug labels has
\end{abstract}

been one of its most powerful tools for protecting the public's health. To encourage appropriate use of prescription drugs, the FDA has sought to ensure that promotional statements make claims about approved indications only and neither overstate the benefits nor understate the risks. A major concern has been finding ways to ensure "fair balance," with adequate attention given to information about risks as well as benefits. When this balance is not achieved, inappropriate promotional statements can contribute to misuse of drugs, with dangerous consequences.

As communications media have evolved, manufacturers have tended to wait for the FDA to establish explicit codes of acceptable marketing practices before devoting substantial resources to a new medium. Direct-to-consumer advertising in print media proceeded tentatively until the FDA issued a guidance document in 1985 establishing a standard format for providing a "brief summary" of risks. ${ }^{3}$ Prescription-drug advertising in broadcast media was similarly minimal until the FDA's guidance revised the definition of "adequate" risk information in 1997 , and again in 1999, to permit broadcast media to include references to a toll-free number or Web site where consumers could obtain more detailed descriptions of a product's adverse effects. In the wake of these FDA actions, spending on direct-to-consumer advertising mushroomed from \$579 million in 1996 to $\$ 1.3$ billion in 1998 and to over $\$ 4$ billion in 2008 .

In November 2009, the FDA 